\title{
Rapid detection and presumptive identification of Clostridium difficile by $p$-cresol production on a selective medium
}

\author{
KD PHILLIPS, PA ROGERS* \\ From the Public Health Laboratory, Luton and Dunstable Hospital, Luton LU4 ODZ
}

SUMMARY A modification of a selective medium for Clostridium difficile is described. The ability of $\mathrm{Cl}$ difficile to produce $p$-cresol from $p$-hydroxy phenyl acetic acid provides a means for the rapid $+\infty$ sensitive detection and presumptive identification of this species in faecal cultures.

The role of Clostridium difficile and its toxin in the aetiology of pseudomembranous colitis is now firmly established. ${ }^{-7}$ Diagnosis of this disease may be difficult ${ }^{8}$ and is achieved by a combination of clinical and laboratory procedures including sigmoidoscopy and biopsy, screening of faeces for specific toxin, and cultural methods aimed at isolation of the pathogen. A significant innovation in this field was the development by George et al. ${ }^{9}$ of an effective selective medium for $\mathrm{Cl}$ difficile.

Elsden et al. ${ }^{10}$ reported that $\mathrm{Cl}$ difficile produced $p$-cresol as an end-product of tyrosine metabolism and suggested that $p$-hydroxy phenyl acetic acid was the precursor of $p$-cresol in the metabolic pathway. This paper describes a modification of the selective medium of George et al.,9 designed to exploit $p$-cresol production for the rapid, sensitive detection and presumptive identification of $\mathrm{Cl}$ difficile in faecal cultures.

\section{Material and methods}

\section{MEDIUM}

The medium of George et al. ${ }^{9}$ (known as CCFA) comprises a buffered proteose peptone agar base incorporating fructose, neutral red indicator, egg yolk suspension and solutions of cycloserine and cefoxitin. In this study the medium was prepared according to the original specifications but with the following modifications:

The antibiotic concentrations were reduced by half, giving a final concentration in the medium of $250 \mu \mathrm{g} / \mathrm{ml}$ of cycloserine and $8 \mu \mathrm{g} / \mathrm{ml}$ of cefoxitin.

\footnotetext{
*Present address: Department of Microbiology, Fremantle Hospital, Fremantle, Western Australia.

Accepted for publication 29 October 1980
}

A filter-sterilised solution of p-hydroxypheny acetic acid was added to the molten medium with theantibiotic solutions to give a final concentration of $0.1 \% \mathrm{wt} / \mathrm{vol}$.

\section{ORGANISMS}

Seven stock strains of $\mathrm{Cl}$ difficile were employed in this study. These strains had been isolated froms faeces and were identified according to the criteria of Holdeman et al. ${ }^{11}$ In addition, two reference strains of $\mathrm{Cl}$ difficile (NCTC 11223 and NCIB 10666) and a reference strain of $\mathrm{Cl}$ scatologenes (NCTC 9800) were included for comparison in alp investigations. All strains were initially screened fors production of $p$-cresol from tyrosine in an aromatiç. amino acid broth similar to that of Elsden et al. ${ }^{10}$ and subsequently for growth and $p$-cresol production from $p$-hydroxy phenyl acetic acid on modified CCFA medium; $p$-cresol was detected by gas chromatography as described below.

\section{FAECAL SPECIMENS}

One hundred randomly-selected specimens of faeces obtained from patients under investigation for other. bacterial pathogens were cultured directly on th\& modified medium. In addition, two hundred samples. of faeces were obtained from healthy adults (food handlers undergoing statutory screening for carriage of food-poisoning organisms). These specimens were sampled with dry swabs and transferred to peptone water for enrichment. The peptone water cultures were subsequently plated on the modified medium ${ }^{+}$ after $48 \mathrm{~h}$ incubation.

CULTURAL CONDITIONS

All cultures were incubated at $37^{\circ} \mathrm{C}$ for up to $48 \mathrm{~h}$ i⿺ anaerobic jars; anaerobiosis was achieved by meang 
of the evacuation-replacement technique of Willis, ${ }^{12}$ using a gas mixture of $90 \% \mathrm{H}_{2}$ and $10 \% \mathrm{CO}_{2}$.

\section{GAS CHROMATOGRAPHY}

A Pye Unicam 204 Series gas chromatograph equipped with a flame ionisation detector was used for $p$-cresol analysis. A glass analytical column $1.5 \mathrm{~m} \times 4 \mathrm{~mm}$ (internal diameter), was packed with $5 \%$ OV17 on Diatomite CQ (JJ's Chromatography Ltd, Kings Lynn, Norfolk) and was operated isothermally at $110^{\circ} \mathrm{C}$. The injection port and the detector temperatures were maintained at $250^{\circ} \mathrm{C}$. Nitrogen was employed as the carrier gas at a flow rate of $50 \mathrm{ml} / \mathrm{min}$. Attenuation of the instrument was routinely set at $2 \times 10^{2}\left(2 \times 10^{-10} \mathrm{~A}\right.$ fsd $)$. The recorder chart speed was $0.5 \mathrm{~cm} / \mathrm{min}$.

A $p$-cresol standard was prepared in aqueous solution at a concentration of $10 \mu \mathrm{mol} / \mathrm{ml}$. Qualitative analysis was performed by extraction of $p$-cresol from $0.1 \mathrm{ml}$ of the standard solution by $0.5 \mathrm{ml}$ of diethyl ether followed by injection of $1 \mu$ l of the ether extract into the chromatograph (peak $\mathrm{A}$ on Figure).

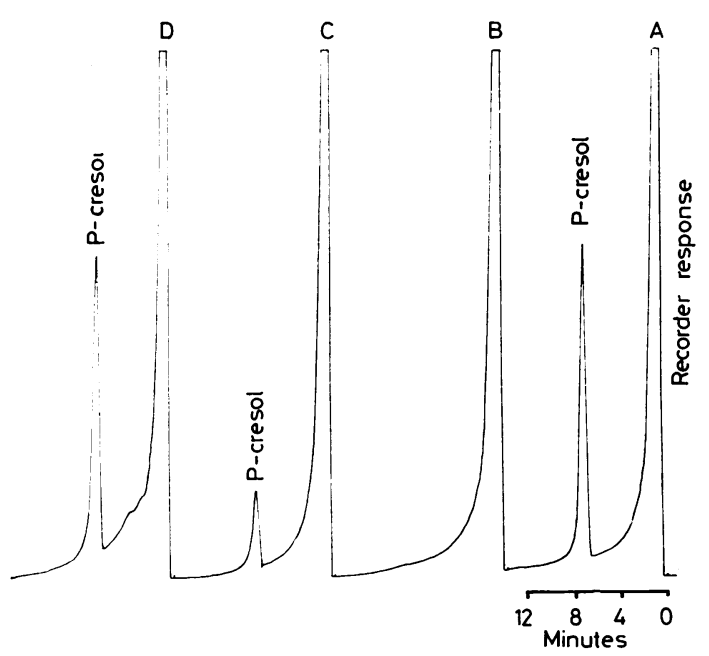

Gas chromatograms of: A p-cresol standard (10 $\mu \mathrm{mol})$ $\mathrm{ml}$ ); B uninoculated medium; C p-cresol production by $C l$ difficile at $24 \mathrm{~h} ; \mathrm{D}$ p-cresol production by Cl difficile at $48 \mathrm{~h}$.

Production of $p$-cresol from $p$-hydroxy phenyl acetic acid by cultures of $\mathrm{Cl}$ difficile on the modified medium was detected as follows: five plugs of agar (total volume approximately $0.1 \mathrm{ml}$ ) were removed by means of a hollow tyne, either from an area of confluent growth or from beneath five discrete colonies and transferred to a test tube. Diethyl ether $(0.5 \mathrm{ml})$ was added and the contents were vortexmixed for $30 \mathrm{~s}$. One microlitre of the clear ether layer was then withdrawn by microsyringe for gas chromatographic analysis of $p$-cresol.

\section{Results}

GROWTH OF STOCK STRAINS

All stock and reference strains of $\mathrm{Cl}$ difficile produced small, but visible colonies after overnight incubation on the modified medium. After further incubation these colonies developed the flat, ground-glass morphology distinctive of this species. In addition all strains of $\mathrm{Cl}$ difficile produced detectable amounts of $p$-cresol from $p$-hydroxy phenyl acetic acid usually within $18 \mathrm{~h}$ on the modified medium (peak $\mathrm{C}$ on Figure): the concentration of $p$-cresol in the medium increased to approximately $10 \mu \mathrm{mol} / \mathrm{ml}$ after $48 \mathrm{~h}$ incubation (peak D on Figure).

The only other species of Clostridium reported to produce $p$-cresol is $\mathrm{Cl}$ scatologenes. ${ }^{10}$ The only strain of this organism available failed to grow on this selective medium.

\section{ISOLATION OF CL DIFFICILE FROM FAECAL} SPECIMENS

The number of strains of $\mathrm{Cl}$ difficile isolated from patients suspected of harbouring intestinal pathogens is shown in Table 1 . None of these patients was diagnosed as having pseudomembranous colitis. All clinical specimens were directly cultured on the modified medium and were incubated for periods varying between 18 and $48 \mathrm{~h}$. In most instances, specimens containing $\mathrm{Cl}$ difficile yielded a moderate to heavy growth of the organism. Some loss of selectivity was apparent as a consequence of the lowered antibiotic concentrations, particularly in heavily inoculated areas; colonies of $\mathrm{Cl}$ difficile nevertheless were usually apparent on other areas of the medium and could be presumptively identified by detection of $p$-cresol. Culture of three specimens yielded only one or two colonies of the organism. These colonies were apparent only after $48 \mathrm{~h}$ incubation and although they were largely obscured by unsuppressed intestinal flora, they could be readily detected and identified by $p$-cresol production. All strains of $\mathrm{Cl}$ difficile isolated were subsequently identified by the criteria of Holdeman et al.11 No other species of Clostridium was isolated from these faecal cultures. Under standard conditions of test

Table 1 Isolation rates of Cl difficile from patients' faeces

\begin{tabular}{llll}
\hline & No of specimens & No of isolates & $\%$ isolation rate \\
\hline Infants ( < 1 year) & 16 & 7 & 43.6 \\
Others ( $>$ 1 year) & 84 & 4 & 4.8 \\
\hline
\end{tabular}


there were no false-positive or false-negative results, nor was $p$-cresol produced in the uninoculated medium (peak B on Figure). The isolation rate of $\mathrm{Cl}$ difficile from normal adult faeces is shown in Table 2.

Table 2 Isolation rate of $\mathrm{Cl}$ difficile from normal adult faeces

\begin{tabular}{lll}
\hline No of specimens & No of isolates & $\%$ isolation rate \\
\hline 200 & 4 & 2 \\
\hline
\end{tabular}

\section{Discussion}

In a comprehensive survey of the amino acid fermenting clostridia, Elsden et al. ${ }^{10}$ found that $\mathrm{Cl}$ difficile possessed the ability to produce $p$-cresol from tyrosine. This characteristic appears to be shared only with $\mathrm{Cl}$ scatologenes, an observation which was confirmed in this study.

In a preliminary investigation, $0.2 \% \mathrm{wt} / \mathrm{vol}$ of L-tyrosine was incorporated in the selective medium. Stock strains of $\mathrm{Cl}$ difficile however failed to produce detectable amounts of $p$-cresol within $48 \mathrm{~h}$. Accordingly $p$-hydroxy phenyl acetic acid was substituted for L-tyrosine in an attempt to obtain positive results. After overnight incubation of primary cultures of $\mathrm{Cl}$ difficile, $p$-cresol was usually detectable in the modified selective medium by gas chromatography. Moreover, the distinctive odour of $p$-cresol was often discernible on examination of culture plates, making gas chromatography essentially confirmatory.

The antibiotic concentrations as specified by George et al. ${ }^{9}(500 \mu \mathrm{g} / \mathrm{ml}$ of cycloserine and 16 $\mu \mathrm{g} / \mathrm{ml}$ of cefoxitin) were halved in this study because the unmodified medium reduced qualitatively and quantitatively the growth of stock strains of $\mathrm{Cl}$ difficile. As a result of using lowered concentrations of antibiotics, some growth of extraneous faecal flora was observed. The loss of selectivity is inevitable, but was acceptable in the light of the positive results obtained.

The isolation of $\mathrm{Cl}$ difficile from patients with diarrhoea but without obvious pseudomembranous colitis is of special interest, since Larson ${ }^{13}$ has suggested that these patients may represent an extension of the clinical spectrum of disease in which $\mathrm{Cl}$ difficile is implicated. From the results of the present investigation it appears that in healthy adults there is a carriage rate of $\mathrm{Cl}$ difficile of approximately $2 \%$. The high carriage rate among infant patients suggests this may be a normal phenomenon. ${ }^{14}$

Presumptive identification of $\mathrm{Cl}$ difficile is currently based on distinctive microscopic and colonial morphology, which may require $48 \mathrm{~h}$ incubation. Gas chromatographic detection of $p$-cresol in the new medium provides a specific and sensitive chemical marker for this species in the absence of mature colony development.

We sincerely thank Dr AT Willis for his advice and encouragement in this study, Maria Senjack for secretarial assistance, and John Harrison, medical photographer, for the illustration.

PA Rogers acknowledges the support given by the Rotary Foundation of Rotary International. This $\vec{\omega}$ took the form of a Foundation Fellowship for study abroad.

\section{References}

1 Larson HE, Parry JV, Price AB, et al. Undescribed toxin in $\stackrel{\mathrm{N}}{\mathrm{O}}$ pseudomembranous colitis. Br Med J 1977;i :1246-8

${ }^{2}$ Rifkin GD, Fekety FR, Silva J, Sack RB. Antibioticinduced colitis. Implication of a toxin neutralised by $\vec{c}$ Clostridium sordellii antitoxin. Lancet 1977;ii:1103-6.

${ }^{3}$ Larson HE, Price AB. Pseudomembranous colitis: presence of clostridial toxin. Lancet 1977;ii:1312-4.

+ Bartlett JG, Chang TW, Gurwith M, Gorbach SL, $\overrightarrow{0}$ Onderdonk AB. Antibiotic-associated pseudomembranous colitis due to toxin-producing clostridia. $N$ Engl $J$ Med 1978;298:531-4.

${ }^{5}$ George RH, Symonds JM, Dimock F, et al. Identification of Clostridium difficile as a cause of pseudomembranous $\bar{\partial}$ colitis. $\mathrm{Br}$ Med J 1978;i:695.

${ }^{6}$ Larson HE, Price AB, Honour P, Borriello SP. Clostridium difficile and the aetiology of pseudomembranous colitis. Lancet 1978 ; i:1063-6.

7 George WL, Sutter VL, Goldstein EJC, Ludwig SL, Oํㅗㅇ Finegold SM. Aetiology of antimicrobial-agentassociated colitis. Lancet $1978 ; \mathrm{i}: 802-3$.

${ }^{8}$ Kappas A, Shinagawa $\mathrm{N}$, Arabi $\mathrm{Y}$, et al. Diagnosis of pseudomembranous colitis. $\mathrm{Br}$ Med J 1978;i:675-8.

9 George WL, Sutter VL, Citron D, Finegold SM. Selective $\bigcirc$ and differential medium for isolation of Clostridium $\overline{0}$ difficile. J Clin Microbiol 1979;9:214-9.

10 Elsden SR, Hilton MG, Waller JM. The end products of the metabolism of aromatic amino acids by Clostridia. Arch 윽 Microbiol 1976;107:283-8.

11 Holdeman LV, Cato EP, Moore WEC, eds. Anaerobe 0 Laboratory Manual. 4th ed. Blacksburg: Virginia Polytechnic and State University, 1977.

12 Willis AT. Anaerobic Bacteriology: Clinical and Laboratory Practice. 3rd ed. London: Butterworth, 1977.

${ }^{13}$ Larson HE. Pseudomembranous colitis is an infection. J Infect Dis 1979;1:221-6.

14 Hall IC, O'Toole E. Intestinal flora in newborn infants with a description of a new pathogenic anaerobe $\omega$ Bacillus difficilis. Am J Dis Child 1935;49:390-402.

Requests for reprints to: Mr KD Phillips, Public Health Laboratory, Luton \& Dunstable Hospital, Lewsey Road, $\frac{O}{\mathbb{D}}$ Luton, Beds LU4 0DZ, England. 